\title{
Nem toda pessoa cega lê em Braille nem toda pessoa surda se comunica em língua de sinais
}

\author{
Elisabeth Fátima Torres \\ Alberto Angel Mazzoni \\ Anahi Guedes de Mello \\ Universidade Federal de Santa Catarina
}

\author{
Correspondência: \\ Elisabeth Fátima Torres \\ Univ. Federal de Santa Catarina \\ Cx. Postal 476 \\ 88040-900 - Florianópolis - SC \\ e-mail: bethtorres@rexlab.ufsc.br
}

\section{Resumo}

0 trabalho foi definido tendo como objetivo discutir e explicitar algumas das diferenças existentes, quanto ao acesso à informação e à comunicação, entre aquelas pessoas que, embora possuam deficiências semelhantes, vivenciam discapacidades diferentes. 0 recorte metodológico aplicado foca especificamente as pessoas com deficiência visual e as com deficiência auditiva, não simultâneas, com ênfase às pessoas com surdez e às com cegueira. 0 arcabouço conceitual utilizado é o mesmo que o adotado pela classificação CIF-OMS, sendo o referencial teórico complementado com os aportes de outros autores que desenvolvem estudos relacionados com o tema da discapacidade. Além das pesquisas bibliográficas, integram a metodologia dados coletados em pesquisas de campo, conduzidas em trabalhos anteriores, e os resultantes de observações de pessoas adultas em situações que demandam por acessibilidade à informação e à comunicação. Os resultados encontrados evidenciam a diversidade existente entre as pessoas com um mesmo tipo de deficiência sensorial e assinalam alguns dos equívocos e prejuízos que podem ocorrer quando essa diversidade não é considerada. Ao longo do texto, fica constatado que as diferenças encontradas entre as pessoas com um mesmo tipo de deficiência sensorial são definidas tanto em função de suas preferências individuais, bem como das limitações e capacidades que são peculiares a cada um desses indivíduos.

\section{Palavras-chave}

Acessibilidade - Cegueira - Diversidade - Surdez. 


\title{
Not every blind person reads Braille and not every deaf person knows sign language
}

\author{
Elisabeth Fátima Torres \\ Alberto Angel Mazzoni \\ Anahi Guedes de Mello \\ Universidade Federal de Santa Catarina
}

Contact:

Elisabeth Fátima Torres

Univ. Federal de Santa Catarina

Cx. Postal 476

88040-900-Florianópolis - SC

e-mail: bethtorres@rexlab.ufsc.br

\begin{abstract}
The objective of this work is to discuss and explain some differences that exist regarding the access to information and to communication among those people who, despite having similar handicaps, experience different inabilities. The methodological approach used here focuses specifically on people with non-simultaneous visual or hearing impairments, with an emphasis on blind or deaf people.

The conceptual framework used is the same one adopted by the ICF$\mathrm{WHO}$ classification, and the theoretical framework is complemented with the contributions from other authors which have developed studies related to the issue of inabilities. In addition to bibliographical research, the methodology is supplemented with data collected in observations of adult people in situations that require access to information and to communication. The results have revealed the diversity existing among people with the same type of sensorial impairment, and point out some of the mistakes and damage that may ensue when such diversity is not taken into account. Throughout the text it becomes clear that the differences found among people with the same kind of sensorial difficulty are defined both by their individual preferences and by the limitations and abilities peculiar to each one of them.
\end{abstract}

\section{Keywords}

Accessibility - Blindness - Diversity - Deafness

* The authors are members of the research group on Accessibility and Technologies of the Remote Experimentation Laboratory of the Universidade Federal de Santa Catarina. 
0 conceito de diversidade humana, na sua acepção mais ampla, abrange várias facetas da constituição dos grupos sociais humanos, entre as quais se pode mencionar a cultura, a religião e o idioma. Algumas características corporais dos seres humanos, tais como: a cor da pele e dos cabelos, os aspectos antropométricos, a idade e várias características genéticas, integram também esse conceito.

Um outro dos aspectos constituintes da diversidade humana diz respeito às discapacidades ${ }^{1}$ que as pessoas podem apresentar, embora algumas destas muitas vezes nem sejam percebidas pelas demais pessoas. Isso costuma acontecer no dia-adia, por exemplo, quando nos relacionamos com pessoas que possuem daltonismo, geralmente sem observarmos as dificuldades que enfrentam e, até mesmo, sem identificarmos que elas possuem essa deficiência visual. Por outro lado, algumas outras discapacidades raramente passam despercebidas, principalmente quando existem elementos exteriores que assinalam a existência da deficiência, como ocorre no caso do uso de uma cadeira de rodas, de uma muleta ou de uma bengala branca.

Embora grande parte dos esforços dos integrantes do movimento das pessoas com deficiência seja conduzido com o objetivo de mostrar à sociedade que a deficiência é um dos componentes da diversidade humana, uma outra grande luta está sendo conduzida por esse movimento: a referente ao direito à informação e à comunicação. Algumas dessas pessoas, principalmente aquelas que possuem deficiência associada à visão ou à audição, empenham-se para mostrar que existe uma outra diversidade, aquela que faz com que, mesmo em situações de deficiências iguais ou semelhantes, as pessoas tenham limitações distintas e necessidades diferentes quanto ao acesso à informação e à comunicação. Isso é devido ao fato de as pessoas que possuem deficiências corporais semelhantes poderem ser diferentes quanto à forma como desempenham suas atividades e participam socialmente, ou seja, elas são diferentes quanto ao aspecto da discapacidade que vivenciam.
Há que se observar que, no dia-a-dia, para o desempenho das atividades cotidianas e para o exercício do direito e dever de participação social, as pessoas se defrontam tanto com facilitadores bem como com barreiras. Esses conceitos, que foram apresentados pela Organização Mundial de Saúde - OMS - (2006), por meio do documento denominado Classificação Internacional de Funcionalidade, Incapacidade e Saúde (CIF), são de aplicação universal, referindo-se, portanto, a todas as pessoas e não apenas àquelas que possuem discapacidades (OMS, 2001).

Da classificação CIF-OMS, advém uma nova abordagem para a análise do conjunto de aspectos que estão relacionados com a saúde, os quais se encontram especificados em quatro componentes: as funções e estruturas corporais; a atividade e participação; os fatores ambientais; e os fatores pessoais. Os três primeiros componentes encontram-se tipificados pela CIF-OMS, ao passo que os fatores pessoais ficaram para serem detalhados em documentos posteriores. Os fatores pessoais são determinantes para a existência de tantas diferenças comportamentais entre os seres humanos, situação esta que se reflete também no fato de pessoas que possuem um mesmo tipo de deficiência poderem apresentar discapacidades diferentes.

Por sua vez, os fatores ambientais podem exercer uma notável influência sobre os níveis de atividade e participação das pessoas, devido ao fato de ser, no meio ambiente, o espaço de convivência no qual as pessoas desenvolvem suas atividades cotidianas e estabelecem as inter-relações que as barreiras e os facilitadores podem estar presentes. Cabe observar que aquilo que se constitui em uma barreira para uma determinada pessoa, pode não o ser para outra, podendo inclusive constituir-se em um facilitador para uma terceira pessoa. Além do ambiente natural e do meio físico construído, são considerados como fatores ambientais: os apoios (tanto o humano

1. Discapacidade é um neologismo e está sendo usado como tradução para a palavra espanhola discapacidad e para a inglesa disability. 
como o animal); os produtos e as tecnologias de ajuda; os serviços de ajuda estabelecidos em políticas públicas; e as atitudes das pessoas, com as quais se estabelecem as relações.

Sempre que é mencionada a existência de barreiras, há que se destacar aquelas que impedem o acesso à informação e à comunicação. A luta pelo direito de acesso à informação e à comunicação ganhou maior impulso no século XX, devido à disseminação do uso das tecnologias associadas a sistemas de computação digital. A comunicação interpessoal, que antes sucedia principalmente de forma direta, ganhou novas dimensões com o uso dessas tecnologias e, atualmente, como grande parte do processo de comunicação ocorre a distância, já não se pode separar o acesso à comunicação do acesso à informação. É necessário observar que informação e comunicação são conceitos que estão imbricados, sendo a informação a matéria-prima para o processo de comunicação.

As tecnologias da Internet e da telefonia através das mensagens de texto permitem atualmente, inclusive com o uso de ajudas técnicas adequadas, a comunicação direta e instantânea entre pessoas com deficiências sensoriais distintas. Pode ocorrer, por exemplo, que uma delas seja cega e a outra surda ${ }^{2}$, e essa comunicação pode se realizar mediante o idioma que essas pessoas optem em utilizar, sendo desnecessário conhecimentos sobre Braille ou sobre língua de sinais para tanto. Devido a isso, pode-se considerar que o maior obstáculo enfrentado pelas pessoas com deficiência nos dias atuais, quando a informação é caracterizada como uma riqueza, está no acesso a ela e, conseqüentemente, a aspectos importantes relacionados à informação, tais como: a educação, o trabalho e o lazer.

\section{Caracterização do problema e discussão teórica}

0 modelo de componentes da CIF-OMS pode ser representado por meio de um sistema de coordenadas cartesianas tridimensionais, no qual, tendo em vista a uma determinada pessoa, o eixo $X$ representa os fatores ambientais com os quais ela convive, o eixo $\mathrm{Y}$ representa a atividade e a participação desse indivíduo nesse ambiente, e o eixo $\mathrm{Z}$ representa a componente corporal dessa pessoa. Os pontos constitutivos desse espaço tridimensional repre-

2. Salvo referência explícita, os substantivos surdez/surdo e cegueira/ cego, e suas derivações, serão usados ao longo do texto conforme as acepções lexicais associadas à ausência, perda ou diminuição considerável do sentido da audição e da visão, respectivamente.

\section{Figura 1: Representação do modelo de escalas discriminadas na CIF.}

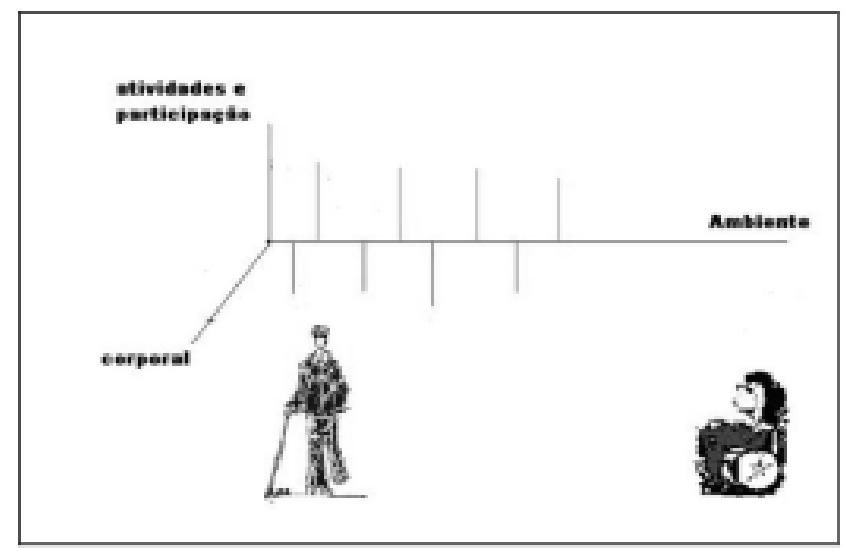

Fonte: Mazzoni, 2003, p. 19. 
sentam cada um dos seres humanos, com a singularidade específica e possivel de ser representada, dentro desse coletivo. Os facilitadores indicam valores positivos encontrados nesse ambiente e são representados por linhas verticais, acima do eixo $\mathrm{X}$, ao passo que as barreiras são representadas pelas linhas verticais situadas abaixo desse eixo, por indicarem os valores negativos (Mazzoni, 2003).

É nesse espaço, o qual representa os distintos ambientes de convivência existentes em uma sociedade, que se encontram as barreiras e os facilitadores. Como já foi destacado, aquilo que é considerado como sendo um facilitador, por uma determinada pessoa, pode não o ser para uma outra, mesmo que ambas tenham o mesmo tipo de deficiência. Tome-se, como exemplo, os filmes com som original em idioma estrangeiro, e que são transmitidos nesse idioma acompanhados de legendas em português. Nesse exemplo, a opção pela transmissão com o som original, associado com legendas em português, pode ser considerado como um facilitador por algumas pessoas surdas e, por outro lado, como uma barreira por aquelas pessoas que têm dificuldades ou estão impossibilitadas para a atividade de recepção de mensagens escritas, como é o caso das pessoas cegas, das disléxicas, dos analfabetos e das pessoas com poucos conhecimentos sobre o português, entre outras.

Cabe observar que algumas pessoas com deficiência sensorial, em determinadas circunstâncias e mediante esforços próprios, conseguem ultrapassar certas barreiras que encontram quanto ao acesso à informação e à comunicação. A necessidade de superar os obstáculos, por conta própria, é uma situação comum e cotidiana a muitas pessoas cegas que - apenas graças ao seu esforço pessoal, ou seja, com um sobreesforço indevido - conseguem obter algumas informações em sítios da web malprojetados e, da mesma forma, comunicar-se via Internet, muitas vezes em ambientes que foram projetados ignorando a existência dessas pessoas (Gutiérrez, 2005). Em situação semelhante, encontram-se muitas das pessoas surdas, ou seja, as suas necessidades específicas quanto à comunicação e ao acesso à informação são ignoradas.

As barreiras à comunicação enfrentadas pelas pessoas surdas passam muitas vezes despercebidas pelas demais pessoas devido ao fato de muitas dessas barreiras serem de caráter ambiental. Para Cañon (2005), o tema da acessibilidade à informação e à comunicação das pessoas surdas deve ser tratado de uma forma transversal, sendo necessário abordar vários aspectos, tais como: a forma como se escuta, os recursos para aumento da visibilidade do ambiente, o contraste de cores, a legendagem e a língua de sinais, entre outros.

As pessoas com baixa visão também se deparam com diversas barreiras ambientais, tais como: pisos irregulares, portas de vidro, portas com espelhos e portas com a mesma tonalidade que a do piso (Mazzoni, 2003). Da mesma maneira, as pessoas com deficiência auditiva ${ }^{3}$ necessitam que haja uma iluminação de boa qualidade nos ambientes. Assim como as pessoas com cegueira, as pessoas com baixa visão enfrentam grandes barreiras referentes ao acesso à informação e à comunicação.

Manzaneda Gonzáles e Mendoza Janco (2003) consideram que as necessidades mais urgentes do grupo das pessoas com deficiência visual ${ }^{4}$, além da sensibilização da sociedade, diz respeito à necessidade de que elas tenham acesso a recursos tecnológicos. Esses autores opinam também que, ao contrário do que muitos pensam, essas deficiências, ao invés de isolar essas pessoas, as impulsionam a consu-

\footnotetext{
3. 0 conceito de deficiência auditiva que é utilizado ao longo do texto, salvo referência explícita, corresponde ao definido pela OMS (2001). Cabe observar que a definição empregada nos documentos legais brasileiros, vigente por meio do Decreto nº 3.298/1999, é: "Deficiência auditiva - perda bilateral, parcial ou total, de quarenta e um decibéis (dB) ou mais, aferida por audiograma nas freqüências de $500 \mathrm{~Hz}, 1.000 \mathrm{~Hz}, 2.000 \mathrm{~Hz}$ e $3.000 \mathrm{~Hz}$ ".

4. 0 conceito de deficiência visual que é utilizado ao longo do texto, salvo referência explícita, corresponde ao definido pela OMS (2001). Cabe observar que a definição empregada nos documentos legais brasileiros, vigente por meio do Decreto n 3.298/1999, é: "Deficiência visual: cegueira, na qual a acuidade visual é igual ou menor que 0,05 no melhor olho, com a melhor correção óptica; a baixa visão, que significa acuidade visual entre 0,3 e 0,05 no melhor olho, com a melhor correção óptica; os casos nos quais a somatória da medida do campo visual em ambos os olhos for igual ou menor que $60^{\circ}$; ou a ocorrência simultânea de quaisquer das condições anteriores".
} 
mir o maior volume de informações que possam adquirir para o seu desenvolvimento.

No Brasil, anteriormente à publicação do Decreto 5.296 de dezembro de 2004, não havia um reconhecimento explícito à existência da diversidade entre pessoas com deficiências semelhantes, tanto no caso da surdez como no da cegueira. Esse decreto inovou ao assinalar o reconhecimento da existência de pessoas surdas que não se comunicam por meio da língua de sinais e ao determinar a necessidade do uso de ajudas técnicas não convencionais, prevendo incentivos ao desenvolvimento delas.

\section{Objetivos e contexto da investigação}

A pesquisa foi elaborada tendo como objetivo discutir e explicitar as diferenças existentes, quanto ao acesso à informação e à comunicação, entre pessoas que, embora possuam deficiências semelhantes, vivenciam discapacidades diferentes. 0 recorte metodológico foca especificamente as pessoas com deficiência visual e as com deficiência auditiva, não simultânea, dando ênfase às pessoas com surdez e às com cegueira.

A partir do referencial teórico propiciado pela CIF-OMS, são analisadas algumas peculiaridades observadas entre esses grupos de pessoas, quanto às limitações que elas manifestam nas áreas vitais ${ }^{5}$ correspondentes à comunicação e à aplicação de conhecimentos. São abordados os aspectos referentes à recepção e à produção de mensagens por sujeitos que ultrapassaram a fase de aprendizagem básica, que é imprescindivel para a recepção e produção de mensagens com autonomia.

0 trabalho é resultante de pesquisas de campo, desenvolvidas em um trabalho específico (Mazzoni, 2003), de observações realizadas pelos autores no desenvolvimento de diversos outros trabalhos e de informações obtidas mediante levantamentos e revisões bibliográficas sobre documentos referentes à acessibilidade à informação e à comunicação.

\section{Resultados e discussão}

São analisados alguns aspectos que evidenciam a diversidade existente entre as pessoas, demonstrando-se, dessa maneira, que o grupo das pessoas que possuem deficiência visual é um grupo heterogêneo no que se refere às suas necessidades específicas quanto ao acesso à informação e à comunicação, assim como também o é o grupo das pessoas que possuem deficiência auditiva. A inobservância das diferenças existentes entre pessoas com um mesmo tipo de deficiência freqüentemente conduz a equívocos, alguns deles refletidos inclusive em documentos legais, bem como a uma inadequada utilização de recursos humanos, financeiros e tecnológicos.

Na seqüência, são apresentadas algumas das implicações da ignorância, ou da não observação, das diferenças individuais existentes entre pessoas que embora possuam deficiências semelhantes vivenciam discapacidades diferentes. Um enfoque especial é dado à observação dessas diferenças em contextos educacionais, com ênfase aos ambientes de ensino de nível superior.

\section{A diversidade existente na deficiência auditiva}

A deficiência auditiva (DA) pode ser caracterizada de diferentes formas, e a escala da audição ${ }^{6}$ apresenta vários graus, sendo que algumas pessoas escutam muito pouco, percebendo apenas sons ambientais de alta intensidade, e outras conseguem ouvir a voz humana, mas não conseguem compreender as palavras, principalmente devido à poluição sonora existente no ambiente. Há, também, aquelas que ouvem sons na faixa das baixas freqüências, o que faz com que percebam apenas partes das palavras, isto é, as palavras ficam soltas e incompletas tal que, conforme re-

5. As áreas vitais relacionadas pela CIF-OMS são: aprendizagem e aplicação de conhecimentos; tarefas e demandas gerais; comunicação; mobilidade; cuidado pessoal; vida doméstica; interações interpessoais; áreas principais da vida; e vida comunitária, cívica e social.

6. A classificação de perdas auditivas é estabelecida conforme tabelas como, por exemplo, a de Davis e Silverman (1970). 
lata Mello (2005), estas vão precisar da leitura labial para completar o que lhes falta no processo de formação sonora das palavras. Os dados do Censo demográfico realizado em 2000 revelam que cerca de $3,5 \%$ da população brasileira possui algum tipo de deficiência auditiva.

No entanto, existem outras diferenças relacionadas com a deficiência auditiva que devem ser destacadas. Monterde Martínez (2004) considera que é importante assinalar que, aos poucos, começa a ser observado que o grupo de pessoas surdas é muito heterogêneo. 0 traço comum é a existência da perda auditiva, que pode ocorrer em distintos graus, mas há matizes sobre ela que precisam ser considerados, tais como: o momento em que ocorre essa perda, o grau da perda auditiva, os recursos (ajudas técnicas e pessoal de apoio) com os quais a pessoa conta para contrabalançar a essa perda, o entorno em que a pessoa se desenvolve, a capacidade de fala e leitura labial dessa pessoa e a preferência dela por um determinado método de comunicação em situações específicas (seja quando esteja com os familiares, na sala de aula, em contato com estranhos etc.).

Essas diferenças determinam distinções nas necessidades e possibilidades de comunicação dessas pessoas. Por exemplo: algumas famílias podem optar em educar uma criança surda prioritariamente pela língua de sinais, enquanto outras contam com recursos que lhes permitem potenciar a comunicação oral para essa criança. Por sua vez, a leitura labial, que pode ser um apoio para diversas pessoas (como é o caso daquelas que possuíam o domínio da língua oral anteriormente à perda auditiva ou a adquiriram posteriormente à perda), pode não ser um meio válido para aquelas outras que tiveram um menor acesso a essa língua e sentem-se inseguras quanto ao uso desta.

Deve também ser ressaltado que a qualidade da leitura labial depende de outros fatores além da habilidade de leitura da pessoa surda, pois tanto o nível de conforto ambiental existente no local em que a conversação é realizada, quanto a capacidade do emissor de articular corretamente os fonemas, ou até mesmo o tipo de grafia labial ${ }^{7}$ do emissor, interferem nesse processo de leitura.

Essas distintas competências e habilidades existentes entre as pessoas com deficiência auditiva, mesmo entre aquelas com um mesmo nivel de perda auditiva, indica a importância de que seja observado, individualmente, não apenas as limitações que estão associadas às deficiências delas, mas também às suas capacidades para o desempenho das atividades diárias.

Quando há interesse em oferecer um ambiente mais favorável às pessoas com DA, uma pergunta deve ser feita: quais são as limitações, que podem ser observadas entre pessoas com DA, para a execução das atividades da vida diária?

Considerando-se as áreas vitais relacionadas pela CIF-OMS, pode-se cogitar que algumas pessoas com DA sintam dificuldades maiores que as sentidas pelas pessoas sem essa deficiência nas áreas de aprendizagem e aplicação de conhecimentos e na de comunicação. Uma vez que tenham sido superados os problemas da aprendizagem básica (que nesse caso podem incluir as atividades de aprender a ler lábios, a vocalizar, a comunicar-se em língua de sinais, a ler, a escrever e a escutar), as demais atividades em que essas pessoas podem manifestar limitações estão relacionadas com o tema da acessibilidade à informação e à comunicação, ou seja, quanto melhor for a acessibilidade existente, em um determinado ambiente, menores serão as dificuldades sentidas pelas pessoas com DA para atuarem nesse ambiente.

No caso da acessibilidade à informação e à comunicação, quando se foca as dificuldades das pessoas surdas, considerações devem ser feitas a respeito dos diferenciais lingüístico-cognitivos encontrados entre elas. Mello e Torres (2005) des-

7. Do mesmo modo que cada pessoa possui sua grafia escrita própria, ela também possui uma grafia labial ou grafia da boca. Contudo, existem indivíduos cuja fala é indetectável por leitura labial, seja porque os movimentos da boca ficam escondidos (por exemplo: devido ao uso de um bigode exagerado ou então ao hábito de falarem mantendo objetos na boca) ou simplesmente porque movimentam a boca de forma tal que sua dicção não pode ser decifrada. 
tacam que a maioria das pesquisas, ao tomarem a surdez como objeto de estudo, não leva em consideração que a pessoa surda é um objeto sujeito eminentemente social, o que implica considerar que as diferenças individuais são constituídas pelas influências sociais, educacionais, culturais e históricas. As diferenças lingüistico-cognitivas ficam mais evidenciadas quando se comparam os surdos oralizados com os não oralizados, conforme 0 texto citado:

São considerados como surdos oralizados aqueles que desenvolveram mais habilidades em linguagem oral, comparativamente aos não oralizados, cujas habilidades verbais são quantitativa e qualitativamente inferiores. A denominação "não oralizado" não é considerada muito precisa para a referência aos sujeitos, porque ser "não oralizado" não equivale à mudez, nem significa que o sujeito surdo não foi exposto ao trabalho de oralização, mas que apenas fala muito pouco, em geral, palavras e frases simples (Botelho, 1998). Simplificando, surdos oralizados são aqueles que usam uma língua oral, onde geralmente a língua-pátria é a sua língua materna, lêem lábios, não se identificam com as manifestações da Cultura Surda e participam mais da Comunidade Ouvinte; os não oralizados usam a língua de sinais como primeira língua (essa pode ter sido ou não sua língua materna) e estão mais fortemente inseridos nos patamares lingüísticosócio-cultural que permeiam a Cultura Surda. (Mello; Torres, 2005)

Devido às diferenças expostas, os recursos para acesso à informação e comunicação, que são reivindicados pelos surdos oralizados, são diferentes daqueles outros em uso pelos surdos não oralizados, sendo que estes, no Brasil, reivindicam prioritariamente a ação de intérpretes da língua de sinais, enquanto os primeiros reivindicam recursos tecnológicos que realizem a transcrição eletrônica, em tempo real $^{8}$, da fala em texto. Serviços de transcrição eletrônica da fala em tempo real para estudan- tes surdos são uma forte realidade em algumas universidades do exterior, como ocorre na Universidade Concórdia, em Montreal - Canadá e, conforme detalha Zenteno (2000), uma das vantagens evidentes oferecida por esse tipo de sistema é a de propiciar uma melhora considerável à língua escrita dos estudantes surdos.

Entre os usuários de línguas de sinais, também existem diferenças específicas que merecem ser evidenciadas. Mediante trabalho compilado por Lewis (2000), a organização britânica Save the Children destaca que cada país, região ou comunidade desenvolve a sua língua de sinais e que, para a organização de eventos nos quais seja necessária a presença de intérpretes de língua de sinais, é preciso assegurar-se de que eles tenham conhecimentos sobre a língua local, bem como estar ciente de algumas das características desse processo de tradução, tais como: que a tradução direta, de ou para a língua de sinais, nem sempre pode ser feita de forma precisa, e que a tradução de palavras complexas ou nomes próprios, quando não exista um sinal para estes, precisará ser feita letra a letra, o que faz com que o processo de comunicação fique lento.

As dificuldades existentes para a expressão de algumas palavras por meio de língua de sinais ficam evidenciadas com os termos técnicos. Por exemplo: pelo fato de não existir um sinal para fenilalanina, cloreto de isobutila e até mesmo um mais complicado como o composto químico denominado ácido 2,4-difluorbenzenossulfônico, quais são as conseqüências para uma pessoa surda que estuda Química e que seja usuário de uma língua de sinais?

A diversidade de interesses existente entre o grupo dos surdos oralizados e o grupo dos usuários de língua de sinais, e as manifestações decorrentes entre esses dois grupos, por ocasião da sanção da Lei n. 10.436/02, foi registrada em um trabalho acadêmico. Dallan

8. Transcrição eletrônica da fala em tempo real: quando esse processo é feito através de digitação, uma pessoa faz anotações relativas às palavras, em um computador, e um software projetado para essa tarefa compõe as palavras e frases. 0 registro deve incluir as falas do palestrante e também as interações que se desenvolvem durante a aula ou palestra. 
(2002) relata que os usuários da Lista dos Intérpretes de Sinais vibraram de felicidade porque era uma conquista que eles já lutavam há anos para conseguir, ao passo que os membros da Lista dos Surdos Oralizados consideraram a referida Lei como sectária e se organizaram em uma carta aberta, de protesto, dirigida aos senadores.

\section{A diversidade existente na deficiência visual}

As funções sensoriais que estão relacionadas com a visão são aquelas que permitem a percepção da presença da luz e a sensação da forma, do tamanho e da cor de um estímulo visual. Contudo, embora as pessoas estejam sujeitas a ter uma deficiência visual (DV) que pode estar associada a quaisquer dessas funções visuais, constata-se que algumas legislações de amparo, tal como a brasileira, só protegem aquelas pessoas que possuem deficiências associadas com as perdas da acuidade visual e do campo visual.

Cerca de 9,5\% da população brasileira possui algum tipo de deficiência visual, conforme os dados apresentados pelo Censo 2000 do Instituto Brasileiro de Geografia e Estatística (2005). Entre estas, muitas são pessoas que possuem baixa visão e, em termos quantitativos, sabe-se que a maioria das pessoas com deficiência visual possui algum grau residual de visão: poucas são totalmente cegas. Gil (2005) considera que, infelizmente, muitas das que têm algum grau de visão são consideradas cegas e tratadas como tal. Dessa forma, perdem os benefícios que o uso da visão residual poderia trazer a seu processo de desenvolvimento e à sua qualidade de vida.

Os fatores contextuais que foram anteriormente relacionados para explicar as diferenças existentes entre as pessoas surdas são, da mesma forma, responsáveis pelas diferenças observadas entre as pessoas com deficiência visual, quanto à forma preferida por elas para o acesso à informação e à comunicação. Essas diferenças, que em parte são devidas à natureza e grau da deficiência, dependem também do nível de escolaridade e da formação adquirida pela pessoa, da fase da vida em que a deficiência se manifestou e dos recursos (ajudas técnicas e pessoal de apoio) que estão disponíveis para essa pessoa.

De forma semelhante ao que ocorre entre as pessoas com DA, uma vez que esteja caracterizada a existência da deficiência visual em uma pessoa, para se atendê-la adequadamente, é necessário que se a observe em suas peculiaridades, tanto no que diz respeito às suas capacidades como às suas limitações. E quais são as limitações que podem ser observadas, entre as pessoas com DV, para a execução das atividades da vida diária?

Tendo como base as áreas vitais relacionadas pela CIF-OMS, é válido cogitar que algumas pessoas com DV sentem dificuldades relevantes nas áreas de aprendizagem e aplicação do conhecimento, mobilidade e comunicação. Superadas as dificuldades referentes à aprendizagem básica (que podem incluir as atividades de aprender a ler, a escrever, a calcular, a orientar-se espacialmente e a deslocar-se com autonomia), constata-se a existência de uma grande dificuldade: a referente ao acesso à informação e à comunicação. Pode-se, inclusive, considerar que a dificuldade de mobilidade, com autonomia, manifestada por essas pessoas, é uma resultante da falta de informações a qual é compreendida, nesse caso, como sendo a ausência ou a fragilidade dos referenciais espaciais.

Para esse amplo grupo de pessoas, às que possuem deficiências visuais severas, a comunicação é fator fundamental para o processo de integração à sociedade, em todos os níveis. Muitas das limitações pessoais relacionadas com a comunicação e a mobilidade foram eliminadas com os atuais recursos tiflológicos, porém existe uma brecha digital que impossibilita que o acesso a esses recursos seja eqüitativo para todas as pessoas com deficiência visual (Manzaneda Gonzáles; Mendoza Janco, 2003).

Atualmente, grande parte dos recursos tiflológicos em uso são ajudas técnicas informáticas. Mazzoni e Torres (2005) constataram que 
as pessoas, quando têm acesso a mais de um recurso tiflológico para acesso à informação e à comunicação, estabelecem preferências entre eles, e que há uma grande empatia com essas ajudas técnicas, embora algumas pessoas ainda manifestem resistência ao uso das tecnologias mais sofisticadas.

Através da pesquisa foi constatado que os entrevistados estabelecem preferências, no que diz respeito ao uso de uma tecnologia sobre outra. Um deles, que necessita de ajuda técnica para a leitura de textos, declarou que prefere ler com os sistemas de leitura de tela, pois desta maneira se sente ativo e, por outro lado, manifestou que, quando estuda utilizando fitas gravadas, sente sonolência. (Mazzoni; Torres, 2005, p. 12)

A citação anterior demonstra algumas das preferências manifestadas pelas pessoas com deficiência visual quanto à forma de ler os documentos. Há que se destacar que, em determinadas situações, as preferências podem ser estabelecidas pela pessoa, como ocorre nos casos em que se prefere um software que tenha uma voz sintetizada mais agradável do que outro, porém, em outras situações. A preferência não é uma resultante da vontade da pessoa e está condicionada às capacidades dela. lsso pode ser observado, por exemplo, na comparação da fluência da leitura em Braille entre pessoas que foram alfabetizadas com esse código e outras que aprenderam o código na idade adulta. As pessoas que têm maior fluência na leitura sentem-se mais à vontade com a leitura de textos impressos em Braille, mesmo que esses textos sejam longos, enquanto as outras preferem utilizar o Braille apenas para pequenos textos.

Por meio de Lewis (2000), a Save the Children alerta que a leitura de um texto impresso em Braille exige mais esforço que a leitura de um texto impresso da forma convencional e indica alguns cuidados que devem ser tomados para a produção desses materiais. Entre as recomendações consta: que seja evita- da a linguagem complexa e que sejam eliminadas as palavras e frases desnecessárias. Por isso, aconselham a produção de documentos concisos e assinalam para a importância de que o conteúdo do documento esteja bem organizado.

É importante destacar que o Braille não é usado por todas as pessoas com deficiência visual. Para usá-lo, faz-se necessário, preliminarmente, que a pessoa seja alfabetizada, contudo, são muitas as pessoas que satisfazem a esse requisito e conhecem o código, porém não o utilizam, por uma questão de impossibilidade, seja porque não conseguiram desenvolver a habilidade tátil que é necessária para essa forma de leitura ou porque perderam parte dessa habilidade tátil (situação que ocorre, por exemplo, quando a irrigação sanguínea nas extremidades dos dedos é inadequada).

Outras, tais como muitas pessoas com baixa visão, mantêm a capacidade de leitura de textos impressos, desde que estes lhes sejam apresentados nas condições adequadas, o que implica tanto em características gráficas (o desenho da fonte, o tamanho dos caracteres, os efeitos de contraste existentes entre o texto e o fundo do texto etc.) bem como em ambientais (a luminosidade, o pano de fundo usado para a leitura etc.).

Aquelas pessoas que mantêm a capacidade de leitura de textos impressos em condições ideais e que têm a possibilidade de utilizar computadores podem considerar como mais adequado o trabalho com textos digitais do que com textos impressos. A popularização do uso dessa tecnologia e as facilidades para edição e processamento de texto propiciadas por ela (tais como: assinalar pontos de interesse, fazer cópias e anotações, pesquisar a ocorrência de termos específicos no texto, construir índices e pesquisar por meio deles etc.) fez com que muitas pessoas cegas também passassem a dar preferência à leitura em textos digitais.

Dentro desse novo contexto tecnológico, o acesso a textos digitais com o uso de ajudas técnicas específicas, tais como software de leitura de tela ou software ampliador de imagens, 
e a estrutura de organização do documento, que é uma característica autoral muito desejável, passam a ter uma importância ainda maior. lsso se deve ao fato de os recursos utilizados para a organização de documentos (tais como títulos, subtítulos, marcadores etc.) serem usados pelos sistemas digitais como metadados. Esses elementos, que contêm dados estruturais sobre o arquivo digital, fornecem informações importantes para a leitura do documento através dos sistemas de leitura de tela e servem também para a montagem de indices e sistemas de busca que permitem a localização de segmentos de texto específicos, que sejam de interesse do leitor, o que implica na otimização da leitura dos documentos.

\section{Implicações educacionais dessa diversidade}

As diferenças existentes entre os seres humanos, no que diz respeito à forma que necessitam ou que preferem que a informação lhes seja transmitida, manifesta-se em distintos contextos. Os meios de comunicação e os ambientes educacionais ilustram bem a necessidade de que haja acessibilidade no processo de comunicação, objetivo esse que só é alcançado quando se conhece e se aplica o princípio da redundância na transmissão da informação. Esse princípio estabelece que informação acessivel é aquela que pode ser captada de forma multissensorial.

Como desdobramento do princípio da redundância, surgiram algumas regras práticas para a transformação da informação, objetivando que aquilo que é captado por um sentido possa ser compreendido também por meio de outros sentidos. Entre as técnicas mais utilizadas para a transformação da informação, podem ser citadas: a transcrição eletrônica das falas em texto em tempo real (gera-se um texto à medida que as pessoas vão falando e o texto resultante poderá ser lido através da tela de um computador ou através de uma linha Braille), a áudio-descrição (consiste em narrar, de uma forma descritiva, os elementos significativos das cenas, das imagens e dos efeitos visuais que se encontram presentes em um determinado ambiente) e a transcrição gestual em língua de sinais (o conteúdo das falas e dos efeitos sonoros é interpretado e transmitido por meio de uma língua de sinais).

Atualmente, a necessidade da acessibilidade à informação pode ser observada em vários misteres além daqueles referentes aos meios de comunicação e aos ambientes educacionais, pois são muitos os profissionais, de distintas áreas, que produzem conteúdos, principalmente digitais, como materiais a serem divulgados via CDs, páginas web e sítios eletrônicos. Devido a isso, é importante assinalar que, individualmente, cada pessoa pode contribuir para a acessibilidade à informação, adotando medidas tais como: evitar a divulgação de informações manuscritas (tendo em vista que os software mais usualmente utilizados para o reconhecimento ótico dos caracteres apresentam muitas falhas com esses documentos); preparar e distribuir apontamentos contendo o resumo de suas idéias sempre que for falar em público (pois esses textos permitem a captação e facilitam a compreensão das idéias expostas); usar a palavra sempre de forma individual e em um ambiente em que haja iluminação para o orador (porque tanto os sistemas de gravação de som e imagem bem como as pessoas com deficiência auditiva necessitam focar o orador); e manter uma postura corporal que favoreça aos interlocutores, ao público e aos sistemas de gravação (já que os deslocamentos em cena e os movimentos da cabeça prejudicam a captação da informação).

\section{O processamento da informação em ambientes de aprendizagem}

Em ambientes educacionais, as pessoas que estão na posição de aprendizes necessitam processar a informação por meio de um conjunto de ações que ocorrem em tempos distintos. Além da ação básica de captar a informa- 
ção, é necessário também fazer algum registro sobre ela (os apontamentos pessoais) para que posteriormente possa ser feito, por esse aluno, o estudo e a revisão do assunto pertinente.

Observa-se que tanto as pessoas com deficiência visual bem como as pessoas com deficiência auditiva enfrentam diversas dificuldades para processar a informação, dificuldades essas que podem se manifestar como mais graves em uma dessas ações e que são percebidas com intensidades distintas, conforme o indivíduo.

Para que a informação possa ser captada por uma pessoa com deficiência sensorial, uma das exigências e recomendações é que ela seja transmitida com redundância, ou seja, deve-se transformar os estímulos visuais em estímulos táteis e sonoros ou aplicar outra transformação adequada entre esses estímulos. Contudo, além da transmissão com redundância, é necessário também que a pessoa concentre a sua atenção para a captação da informação, o que pode gerar o problema da atenção dividida. Esse tipo de problema foi relatado por Alcantud Marin (2000), referindo-se aos estudantes surdos de sua universidade que não dispunham de um sistema de ajuda para fazer os apontamentos referentes às aulas das quais participavam e que, por isso, eram obrigados a manter uma atenção dividida já que, por uma parte, precisavam observar o professor para fazer a leitura labial e, por outra parte, deviam fixar a vista em seu caderno para fazer as anotações.

Esse problema, de precisar dividir a atenção, é enfrentado também por outros alunos, como aqueles que prestam atenção simultânea ao conteúdo exposto pelo mestre e ao intérprete de língua de sinais e também por aqueles outros que, sem enxergar, além de ouvir a aula, precisam estar atentos para compreender as pistas visuais que vão surgindo e fazer os apontamentos correspondentes.

Ajudas técnicas adequadas, como os sistemas usados para a transcrição de falas em texto em tempo real, eliminam esse problema da atenção dividida e podem gerar benefícios também para outros alunos. Zenteno (2000) rela- ta que o sistema de apontamentos eletrônico tem sido difundido, no contexto colegial e universitário, e popularizado e está se convertendo rapidamente no meio de comunicação preferido por muitos estudantes surdos e por aqueles com perda auditiva média.

Há que se observar que os sistemas atuais de transmissão automática das falas em texto, além de permitirem que as pessoas com DA acompanhem, em tempo real, as falas que vão sendo transcritas em textos, geram também arquivos digitais com o conteúdo desses textos. Constituem-se, devido a essa peculiaridade, em sistemas que atendem integralmente àquelas necessidades de processamento de informação que são sentidas, em ambientes de aprendizagem, por todas as pessoas. Esses sistemas podem ser caracterizados como sendo imprescindíveis para algumas pessoas com DA, para que possam realizar a ação de captar a informação e, ao mesmo tempo, serem um recurso auxiliar para várias outras pessoas que não possuem esse tipo de deficiência, nessa mesma ação. Por outro lado, os arquivos digitais gerados durante esse processo são indispensáveis para que muitas pessoas com DV revejam e estudem os apontamentos e, simultaneamente, se constituem em um recurso que é altamente desejável, por vários outros alunos, durante a fase da revisão da matéria em estudo.

\section{Aspectos relacionados com a orientação legal}

Dentre os autores anteriormente citados, Alcantud Marin (2000) e Zenteno (2000) relatam situações que estão tecnologicamente muito distantes da nossa realidade e que foram observadas na Espanha e no Canadá, respectivamente. Para abordar a situação atual, no Brasil, é necessário apresentar alguns dos documentos legais existentes relacionados com essa temática.

Observa-se que os dispositivos legais brasileiros passaram a contemplar o tema da acessibilidade, de forma mais ampla, a partir da Lei n. 10.098, publicada em 2000, a qual esta- 
belece normas gerais e critérios básicos para a promoção da acessibilidade. Contudo, a regulamentação dessa lei foi feita apenas em 2004, por meio do Decreto n. 5.296.

Anteriormente a esses documentos, em alguns outros textos legais de abrangência restrita, são encontradas algumas referências à acessibilidade como, por exemplo, em portarias editadas pelo Ministério da Educação (MEC), em 1999 e em 2003, e que tiveram como súmula orientar as instituições de Ensino Superior, quanto a alguns requisitos mínimos de acessibilidade, a serem observados por essas instituições, para instruir os processos de autorização e de reconhecimento de cursos e os de credenciamento de instituições. Uma análise detalhada desse conjunto de documentos legais do MEC evidencia que a diversidade existente entre pessoas com deficiências semelhantes nem sempre é observada.

0 mais recente documento legal que contempla o tema da acessibilidade, de forma abrangente, é o Decreto n. 5.296/04 e, embora não conste a expressão surdo oralizado, inova-se ao admitir a necessidade da existência de serviços de atendimento para aquelas pessoas com deficiência auditiva que não se comunicam em língua gestual.

Contraditoriamente ao avanço que foi observado quando da redação do Decreto n. 5.296, no que diz respeito à explicitação das diferenças existentes entre pessoas com um mesmo tipo de deficiência sensorial, em fins de 2005, foi aprovado o Decreto n. 5.626, o qual prevê condições especiais de atendimento para aquelas pessoas com deficiência auditiva que são usuárias da língua de sinais, tanto nos serviços que são prestados diretamente pelo poder público, bem como naqueles outros que são prestados por empresas concessionárias de serviços públicos. Como conseqüência da aprovação desse texto, foi criada uma lacuna legal, no que diz respeito ao atendimento a que deveriam ter direito, nesses serviços, tanto as pessoas com DA que não são usuárias da língua de sinais, bem como aquelas outras pessoas que possuem outro tipo de deficiência.

Outro fator que merece ser analisado, ademais das lacunas observadas na redação dos textos legais citados, é o referente às interpretações a que esses textos estão sujeitas, bem como os problemas resultantes dessas interpretações. Esse conjunto de textos legais induz a que se considere que as pessoas surdas, indistintamente, sejam usuárias da língua de sinais e que as pessoas cegas, quando alfabetizadas, tenham o conhecimento e a habilidade que são necessários para se ler textos em Braille.

De forma concomitante, observa-se que tem havido a tendência a se considerar que os requisitos de acessibilidade especificados nos textos que provêm de órgãos públicos estabelecem as condições necessárias e suficientes para se lograr a acessibilidade, tendo, por isso, conduzido a situações que, se não são injustificáveis, certamente geram injustiça ao concederem atendimento diferenciado a uns alunos, com um determinado tipo de deficiência sensorial, e não o concederem a outros alunos, mesmo quando a deficiência é a mesma. Um testemunho sobre uma dessas situações foi registrado por Mazzoni (2003):

Dois alunos, de uma mesma universidade [...] com a mesma deficiência [...], o aluno surdo que necessita do serviço de intérprete de Libras foi atendido, mas o aluno surdo oralizado não o foi. (p. 184)

Além de considerar que os textos legais definem as condições necessárias e suficientes, o que pode ser usado para desqualificar ou negar provimento àquelas outras reivindicações apresentadas pelos alunos que difiram das constantes nesses textos (baseado na presunção de que foi corretamente cumprida a exigência ou recomendação legal), outros problemas podem ocorrer. Entre estes, há que se considerar as conseqüências resultantes da interpretação equivocada de considerar aquilo que deveriam ser as condições mínimas como sendo as condições recomendáveis. A falta de ênfase sobre os recursos tecnológicos, nos textos legais, pode ser usada para exemplificar uma dessas situações: como não há a ênfase, esses 
produtos ficam ausentes dos orçamentos educacionais e isso ocasiona, como conseqüência, que muitos alunos sejam privados do contato e do conhecimento sobre o uso dessas tecnologias nos Ensinos Fundamental e Médio.

Disso podem resultar situações inusitadas, como a que foi relatada por Lara e Campos (2005) referindo-se a um projeto, proposto para o atendimento a universitários com deficiência visual, no qual a instituição de ensino se propunha a oferecer a esses alunos alguns recursos tecnológicos, mas como constataram que os alunos não estavam preparados para usá-los, foi necessário, preliminarmente, capacitar os alunos à utilização deles.

\section{As preferências individuais}

A situação anteriormente relatada, referente a estudantes universitários com deficiência visual e que não tinham tido contato anterior com as ajudas técnicas informáticas, adverte para o fato de que as pessoas só podem manifestar preferências a partir do momento em que tenham tido a possibilidade de conhecer e experimentar as alternativas que lhes estão disponíveis e que atendem às suas necessidades. A pessoa que foi ou está privada do conhecimento sobre essas ajudas técnicas, por exemplo, não pode exercer o seu direito de opção de uma das alternativas sobre as outras.

As preferências, por sua vez, são estabelecidas em função de algumas características pessoais e, para que se possa optar, é necessário satisfazer a alguns requisitos:

1 Saber usar: ter o conhecimento necessário sobre o uso do produto ou da técnica;

2 ter capacidade para usar: uma vez tendo os recursos à disposição, é necessário que se tenha as condições físicas que permitam o uso deles;

3 querer usar: implica sentir-se à vontade com o uso e com os resultados obtidos com a opção elegida.
Outra questão importante, que deve ser observada quando se considera a questão das preferências individuais, está relacionada ao fato de uma pessoa poder variar as suas preferências em função do contexto. As pessoas surdas que fazem uso das línguas de sinais, por exemplo, podem sentir-se bem atendidas em um determinado ambiente quando dispõem do apoio de uma pessoa que atue como intérprete. No entanto, essas mesmas pessoas, em outras situações, podem preferir uma forma distinta de acesso à informação, como a transcrição eletrônica das falas em texto, principalmente quando sabem que, posteriormente, necessitarão processar as informações que estão sendo captadas.

De forma análoga, uma pessoa com deficiência visual que saiba Braille pode preferir ler documentos impressos dessa forma para a conferência de textos que contenham pouca informação, tais como uma conta de consumo de energia elétrica e, em outras situações, optar pelo uso de um sistema de leitura de tela para o trabalho de leitura e escrita de textos técnicos e literários.

As situações de preferência ocorrem quando a pessoa se sente mais à vontade com uma das alternativas de acesso à informação, ou forma de comunicação, do que com outra. Tais preferências devem ser respeitadas por influenciarem na qualidade do desempenho, dessa pessoa, na atividade em curso.

Por outra parte, a existência das limitações individuais adverte para o fato de que algumas pessoas necessitam que a informação Ihes seja transmitida de uma forma estabelecida, para que possam captá-la e compreendê-la, e demonstram que, embora a limitação possa estar associada a uma deficiência específica, ela não é determinada por esta.

Para enfrentar o problema da falta de acessibilidade à informação e à comunicação em ambientes educacionais, é imprescindível estar atento à necessidade de intervenção, sendo que esta pode se fazer necessária nas três seguintes situações: 
1. A pessoa que emite a mensagem precisa estar ciente das suas responsabilidades para o processo da acessibilidade;

2. 0 receptor da mensagem, por sua vez, deve estar familiarizado com o ambiente, as ajudas técnicas e o apoio humano com o qual irá contar nesse ambiente e precisa estar preparado para saber apresentar as suas reivindicações;

3. 0 ambiente no qual ocorre o processo de comunicação deve ser tal que permita a transmissão da informação de forma redundante, devendo-se utilizar, para tanto, as técnicas de transformação da informação, associadas com o uso de ajudas técnicas, e as diversas formas de apoio humano (como as pessoas que lêem em voz alta, as que retransmitem as palavras silenciosamente articulando-as corretamente; as que interpretam as frases e as transmitem em línguas de sinais; as que retransmitem as palavras estimulando de forma tátil ao receptor da mensagem etc.).

Há que se destacar que são nos ambientes educacionais que se encontram os grandes produtores e disseminadores do conhecimento, sendo muito rica, tanto em termos quantitativos como qualitativos, a informação que é transmitida nesses ambientes. Essa informação pode estar contida e ser divulgada por meio de diversos conteúdos, em diferentes formatos e mídias, tais como: áudios-visuais, maquetes, modelos tridimensionais, textos, discursos orais, mapas táteis etc. A pesquisa e o desenvolvimento de soluções que permitem a transmissão, com redundância, de todo esse rico e diversificado conjunto de informações constituem o amplo espaço de trabalho da área de pesquisa em acessibilidade à informação e à comunicação.

No que diz respeito ao processamento da informação verbal, seja ela oral ou escrita, há soluções tecnológicas disponíveis para compra no mercado de software e serviços, tais como os sistemas de transcrição automática de falas em texto e os sistemas de reconhecimento de fala.

Para os meios de comunicação de massa que utilizam a multimídia (Internet, cinema, televisão etc.), há um conjunto de técnicas que permite que as informações relevantes possam ser transmitidas com redundância. Algumas recomendações técnicas ${ }^{9}$, normas e dispositivos legais ${ }^{10}$ disciplinam sobre a acessibilidade nesses meios, e essas soluções podem ser aplicadas e transferidas a outros ambientes, como é o caso dos ambientes educacionais.

\section{Conclusões}

A diversidade existente entre os seres humanos se expressa em distintas formas e é possivel considerar-se, recursivamente, que exista uma diversidade dentro da diversidade. Esse raciocínio conduz a que características individuais tais como deficiências sensoriais específicas sejam consideradas inadequadas para caracterizar coletivos humanos, sempre que se esqueça a diversidade existente entre esse grupo de pessoas.

Tanto a deficiência visual como a deficiência auditiva geram dificuldades para a captação e a compreensão da informação e para os processos de comunicação, e isso se aplica a todos os individuos que possuem essas deficiências. Contudo, o grau de dificuldade manifestado por um indivíduo específico é peculiar a ele e está associado com a discapacidade que vivencia e não com a deficiência que essa pessoa possa ter.

Embora seja verdadeiro que as pessoas cegas não percebam as informações visuais, isso é insuficiente para determinar se uma dessas pessoas, como indivíduo particular, sabe ou não: escrever, ler, desenhar, usar o computador, comunicar-se em idiomas estrangeiros, escrever ou ler em Braille etc. De forma semelhante, sabe-se que as pessoas surdas não compreendem as informações sonoras, porém não se pode inferir, a partir disso, que dentre essas uma pessoa específica saiba ou não: falar, escrever no idioma pátrio, compreender o que conversam diretamente com ela, expressar-se em idioma estrangeiro, expressar e compreender línguas de sinais etc.

9. Como as pautas do World Wide Web Consortium - Web Accessibility Initiative 10. Como o Decreto n. $5.296 / 04$. 
Todas essas possibilidades de ser uma pessoa com cegueira ou com surdez, no que diz respeito ao acesso à informação e à comunicação, devem ser consideradas quando se planeja ou se oferece uma forma de atendimento a elas. É por isso que propostas reducionistas, tais como aquelas que consideram o Braille como sendo uma solução adequada para as pessoas cegas e a língua de sinais, como sendo a solução ideal para a comunicação das pessoas surdas, devem ser evitadas tanto pelo que representam de desrespeito à diversidade de formas de ser dessas pessoas, bem como pelo impacto de sugestões que trazem para a sociedade, que tende a considerar essas propostas, quando provenientes de órgãos públicos, como diretrizes.

Sempre que se procura conhecer qual é a reivindicação que uma pessoa com deficiência sensorial apresenta, para o seu acesso à informação e à comunicação, é fundamental lembrar que as suas preferências estão associadas com aquilo que ela já conhece e sabe usar. Isso explica, por exemplo, o fato de as pessoas que não têm o hábito de usar o computador geralmente sentirem-se desconfortáveis para usar as ajudas técnicas informáticas.

Ao longo do texto, procurou-se dar resposta a uma grande questão: aquela que nos permite responder afirmando que nem toda pessoa cega lê em Braille nem toda pessoa surda se comunica em língua de sinais. Essa resposta poderia ser usada para contestar várias perguntas, tais como: Por que as disposições do MEC referentes à atenção às pessoas com necessidades especiais resultantes de deficiências sensoriais precisam ser revistas? Por que é necessário aplicar o conceito de Desenho para Todos na educação? Por que precisamos da acessibilidade nos meios de comunicação?

Todas essas possíveis perguntas e outras correlatas refletem a existência de problemas, os quais só permanecem como tais devido ao fato de o tema da diversidade existente entre as pessoas com um mesmo tipo de deficiência ser pouco discutido. Esse trabalho, no qual foram abordados alguns dos aspectos pertinentes à diversidade existente entre as pessoas com deficiência auditiva e às com deficiência visual, sem exaurir o tema, conduz a que se medite sobre a necessidade de se estender esse tipo de pesquisa para um contexto maior de discussão, que contemple também outras deficiências, o que deixa em aberto um novo interrogante de pesquisa: Por que é necessário pesquisar sobre a diversidade existente entre as pessoas que possuem deficiências semelhantes? 


\section{Referências bibliográficas}

ALCANTUD MARIN, F. Las tecnologías de ayuda para el acceso a los estudios superiores en la UVEG. In: Congreso Iberoamericano de Informática Educativa Especial, 2, Anais... Córdoba, 2000.

BRASIL. Decreto n. 3.298, de 20 de dezembro 1999. Regulamenta a Lei no 7.853, de 24 de outubro de 1989, dispõe sobre a Política Nacional para a Integração da Pessoa Portadora de Deficiência, consolida as normas de proteção, e dá outras providências. Diário Oficial da União, Brasília, 21 dez. 1999.

BRASIL. Lei n. 10.098 de 19 de dezembro de 2000. Estabelece normas gerais e critérios básicos para a promoção da acessibilidade das pessoas portadoras de deficiência ou com mobilidade reduzida, e dá outras providências. Diário Oficial da União, Brasília, 20 dez. 2000.

BRASIL. Lei n. 10.436 de 24 de abril de 2002. Dispõe sobre a Língua Brasileira de Sinais - Libras e dá outras providências. Diário Oficial da União, Brasília, 25 dez. 2002.

BRASIL. Decreto n. 5.296 de 02 de dezembro de 2004. Regulamenta as Leis n. 10.048, de 8 de novembro de 2000, que dá prioridade de atendimento às pessoas que especifica, e 10.098, de 19 de dezembro de 2000, que estabelece normas gerais e critérios básicos para a promoção da acessibilidade das pessoas portadoras de deficiência ou com mobilidade reduzida, e dá outras providências. Diário Oficial da União, Brasília, 3 dez. 2004.

BRASIL. Decreto n. 5.626, de 22 de dezembro de 2005. Regulamenta a Lei no 10.436, de 24 de abril de 2002, que dispõe sobre a Língua Brasileira de Sinais - Libras, e 0 art. 18 da Lei no 10.098, de 19 de dezembro de 2000. Diário Oficial da União, Brasília, 23 dez. 2005.

CAÑON, L. J. Accesibilidad a la Información y a la comunicación. Confederación Estatal de Personas Sordas. Disponível em: <http://www.cnse.es/comision.php?comision=ACCESIBILIDAD>. Acesso em: 22 ago. 2005.

DALLAN, M. S. S. Educação de Jovens e Adultos: estudo sobre o processo de aquisição do português escrito por alunos surdos. 2002. 95 p. Monografia. Pontifícia Universidade Católica de Campinas, Campinas, 2002.

DAVIS, H.; SILVERMAN, R. S. Hearing and deafness. New York, Holt, Rinehart and Winston, 1970.

GUTIÉRREZ, E. El concepto de esfuerzo indebido. Disponível em: <http://bitacoras.sidar.org/emmanuelle/index.php?2005/06/ 16/11-el-concepto-de-esfuerzo-indebido>. Acesso em: 20 ago. 2005.

GIL, M. Espaç̧os de Inclusão. Disponível em: <http://www.tvebrasil.com.br/salto/boletins2002/ede/edeimp.htm>. Acesso em: 20 ago. 2005.

IBGE. Instituto Brasileiro de Geografia e Estatística. Censo 2000. Disponível em: <http://www.ibge.gov.br/home/estatistica/populacao/ censo2000/populacao/deficiencia_Censo2000.pdf>. Acesso em: 20 ago. 2005.

LARA, A. T.S.; CAMPOS, M. B. A tecnologia móvel aplicada a ambientes de aprendizagem para inclusão de acadêmicos com necessidades educacionais especiais. In: Congreso Iberoamericano de Informática Educativa Especial, 5, Anais... Montevideo, 2005.

LEWIS, I. Access for all: helping to make participatory processes accessible for everyone. Londres: Save the Children, 2000.

MANZANEDA GONZÁLES, F.; MENDOZA JANCO, D. I. Accesibilidad a la comunicación para personas ciegas. In: Congreso Internacional de Bibliotecnología, Documentación y Archivística (CIBDA). Proceedings 2. La Paz, 2003.

MONTERDE MARTÍNEZ, I. Las personas sordas y la comunicación. In: Seminario sobre Medios de Comunicación sin Barreras, VII. Anais... Alfara del Patriarca, 2004.

MAZZONI, A. A. Deficiência x participação: um desafio para as universidades. Tese de Doutorado. Universidade Federal de Santa Catarina, Florianópolis, 2003.

MAZZONI, A. A.; TORRES, E. F. A percepção dos alunos com deficiência visual acerca das barreiras existentes no ambiente 
universitário e seu entorno. Benjamin Constant, Rio de Janeiro: Instituto Benjamin Constant; Ministério da Educação, ano 11, n. 30, p. 10-17, 2005.

MELLO, A. G. Reflexiones de una usuaria de implante coclear: ¿que es lo que yo consigo escuchar? In: Congreso lberoamericano de Informática Educativa Especial, 5, Anais... Montevideo, 2005.

MELLO, A. G.; TORRES, E. F. Accesibilidad en la comunicación para sordos oralizados: contribuciones de las tecnologías de información y comunicación. In: Congreso Iberoamericano de Informática Educativa Especial, 5, Anais... Montevideo, 2005.

OMS. Organização Mundial da Saúde Clasificación Internacional del funcionamiento, de la discapacidad y de la salud. Genebra: OMS, 2001. Disponível em: <http://www.humv.es/uipcs/rhhd/documentos.html>. Acesso em: ago. 2006.

ZENTENO, M. T. El servicio de transcripción electrónica para el estudiante sordo: una experiencia exitosa en la Universidad de Concordia, Montreal, Quebec, Canadá. In: Congresso Iberoamericano de Informática Educativa Especial, 2, Anais... Córdoba, 2000.

Recebido em 24.04.06

Modificado em 13.09.06

Aprovado em 28.09.06

Elisabeth Fátima Torres, doutora e mestre em Engenharia, com especialização em Educação, exerce sua carreira docente como professora universitária, mantém como foco de suas investigações, desde 1997, os temas da acessibilidade, tecnologias de informação e comunicação e pessoas com discapacidade e possui trabalhos publicados referentes às suas pesquisas.

Alberto Angel Mazzoni, doutor em Engenharia, atua como consultor em acessibilidade e tecnologias, com experiência universitária e vasta produção acadêmica relacionada a essa área. E-mail: alberto@rexlab.ufsc.br

Anahi Guedes de Mello, participante em diversas investigações relacionadas com o tema da discapacidade, atua de forma ativa na luta pela defesa dos direitos das pessoas com discapacidade e é estudante universitária. E-mail: anahi@rexlab.ufsc.br 